\title{
Kinetic and Stereochemical Analysis of YwhB, a 4-Oxalocrotonate Tautomerase Homologue in Bacillus subtilis: Mechanistic Implications for the YwhB- and 4-Oxalocrotonate Tautomerase- catalyzed Reactions ${ }^{\dagger}$
}

\author{
Susan C Wang§, William H. Johnson Jr.§, Robert M. Czerwinski, Stacy L. Stamps, and \\ Christian P. Whitman \\ Division of Medicinal Chemistry, College of Pharmacy, The University of Texas, Austin, Texas \\ 78712-1074
}

\begin{abstract}
YwhB, a 4-oxalocrotonate tautomerase (4-OT) homologue in Bacillus subtilis, has no known biological role and the gene has no apparent genomic context. The kinetic and stereochemical properties of YwhB have been examined using available enol and dienol compounds. The kinetic analysis shows that YwhB has a relatively non-specific 1,3- and 1,5-keto-enol tautomerase activity, with the former activity prevailing. Replacement of Pro- 1 or Arg-11 with an alanine significantly reduces or abolishes these activities, implicating both residues as critical ones for the activities. In $\mathrm{D}_{2} \mathrm{O}$, ketonization of two monoacid substrates (2-hydroxy-2,4-pentadienoate and phenylenolpyruvate) produces a mixture of stereoisomers $\left\{2\right.$-keto- $3-\left[{ }^{2} \mathrm{H}\right]-4-$ pentenoate and $3-\left[{ }^{2} \mathrm{H}\right]-$ phenylpyruvate $\}$, where the $(3 R)$-isomers predominate. Ketonization of 2-hydroxy-2,4hexadienedioate, a diacid, in $\mathrm{D}_{2} \mathrm{O}$ affords mostly the opposite enantiomer, $(3 S)$-2-oxo-[3-2H]-4hexenedioate. The mono- and diacids apparently bind in different orientations in the active site of YwhB, but the highly stereoselective nature of the YwhB reaction using a diacid suggests that the biological substrate for YwhB may be a diacid. Moreover, of the three dienols examined, 1,3- and 1,5-keto-enol tautomerization reactions are only observed for 2-hydroxy-2,4-hexadienedioate, indicating that the $\mathrm{C}-3$ and $\mathrm{C}-5$ positions are accessible for protonation in this compound. Incubation of 4-OT with 2-hydroxy-2,4-hexadienedioate in $\mathrm{D}_{2} \mathrm{O}$ results in a racemic mixture of 2-oxo-[3- $\left.{ }^{2} \mathrm{H}\right]-4$ hexenedioate, suggesting that 4-OT may not catalyze a 1,3-keto-enol tautomerization reaction using this dienol. It has previously been shown that 4-OT catalyzes the near stereospecific conversion of 2-hydroxy-2,4-hexadienedioate to $(5 S)-\left[5-{ }^{2} \mathrm{H}\right]$-2-oxo-3-hexenedioate in $\mathrm{D}_{2} \mathrm{O}$. Taken together, these observations suggest that 4-OT might function as a 1,5-keto-enol tautomerase using 2-hydroxy-2,4hexadienedioate.
\end{abstract}

4-Oxalocrotonate tautomerase (4-OT) is encoded by the TOL plasmid pWW0, which is present in various soil bacteria including Pseudomonas putida mt-2 $(1,2)$. The enzyme is part of the meta-fission pathway, which is a catabolic route for the conversion of simple aromatic hydrocarbons to Krebs Cycle intermediates (3). The hexameric enzyme, composed of 62 amino

\footnotetext{
${ }^{\dagger}$ This research was supported by the National Institutes of Health Grants GM-65324 and GM-41239 and the Robert A. Welch Foundation (F-1334). S.C.W. is a Fellow of the American Foundation for Pharmaceutical Education.

*Address correspondence to this author. Tel: 512-471-6198; Fax: 512-232-2606; E-mail: whitman@mail.utexas.edu. $\S$ These authors contributed equally to this work

${ }^{1}$ Abbreviations: Cm, chloramphenicol; dNTP, deoxynucleotide triphosphate; LB, Luria-Bertani; Kn, kanamycin; NMR, nuclear magnetic resonance; 4-OT, 4-oxalocrotonate tautomerase; PCR, polymerase chain reaction; SDS-PAGE, sodium dodecyl sulfate-polyacrylamide gel electrophoresis.
} 
acid monomers, purportedly catalyzes the conversion of 2-oxo-4-hexenedioate (1,Scheme 1$)$ to 2-oxo-3-hexenedioate (3) via the intermediate 2-hydroxy-2,4-hexadienedioate, known commonly as 2-hydroxymuconate (2) (4-7). This reaction, a 1,3-allylic rearrangement, was proposed on the basis of indirect kinetic and stereochemical studies using 2 and other monoand diacid dienols $(4,6,7)$. The conversion of $\mathbf{1}$ to $\mathbf{3}$ cannot be observed directly because $\mathbf{1}$ is not isolable and exists only in rapid equilibrium with 2 (4).

Pro-1, Arg-11, Arg-39 and Phe-50 have been identified as critical residues for 4-OT activity (8-15). In the context of the reaction shown in Scheme 1, Pro-1 functions as the general base and is responsible for removing a proton at C-3 (of $\mathbf{1}$ ) and placing the proton at C-5 (of $\mathbf{3}$ ) (8-11). Arg-11 and Arg-39 interact respectively with the C-6 and C-1 carboxylate groups of the substrate, playing roles in both binding and catalysis $(8,12-14)$. Phe-50 plays a role in maintaining a hydrophobic environment near Pro- 1 and this environment is partially responsible for the low $\mathrm{p} K_{\mathrm{a}}$ of Pro-1 ( 6.4) (15).

YwhB is a closely related 4-OT homologue ( $\sim 36 \%$ sequence identity and $46 \%$ similarity) found in B. subtilis (16). The biological role of YwhB is not known and there is no apparent genomic context to suggest one. However, YwhB functions as an effective 1,3-keto-enol tautomerase, converting 2-hydroxy-2,4-pentadienoate (5,Scheme 1) to 2-oxo-4-pentenoate (4), and phenylenolpyruvate (7,Scheme 2) to phenylpyruvate (9) (17-19). YwhB is also a hexamer, consisting of 61 amino acid monomers (16). The YwhB sequence retains Pro-1 and Arg-11, replaces Phe-50 with a tyrosine, and more significantly, has a valine in place of Arg-39. An inhibition study showed that covalent modification of Pro-1 by 3-bromopropiolate inactivates YwhB, implicating Pro-1 as a critical catalytic residue in the conversion of 7 to 9 (18).

As part of our effort to identify a physiological role for YwhB and define a mechanism, we examined three additional compounds [ 2 , Scheme 1 , ( $p$-hydroxyphenyl)enolpyruvate, $\mathbf{8}$, and 2-hydroxy-2,4-heptadiene-1,7-dioate, 11, Scheme 2)] as potential substrates and carried out a mutagenesis and stereochemical analysis of three YwhB-catalyzed tautomerization reactions ${ }^{2}$. The results indicate that $\mathrm{YwhB}$ is a more efficient 1,3-keto-enol tautomerase than it is a 1,5-keto-enol tautomerase, and that Pro-1 and Arg-11 are critical residues for these two activities. The stereochemical analysis shows different consequences for the monoacids ( $\mathbf{5}$ and 7) and the diacid, 2, possibly reflecting different binding modes in the active site of YwhB. In $\mathrm{D}_{2} \mathrm{O}$, YwhB processes 5 and $\mathbf{7}$ to a mixture of the $3 R$ - and $3 S$-isomers of $\left[3-{ }^{2} \mathrm{H}\right]-\mathbf{4}$ and $\left[3-{ }^{2} \mathrm{H}\right]-9$, respectively, with the $3 R$ isomers predominating. In contrast, YwhB converts 2 to the $3 S$ isomer of $\left[3-{ }^{2} \mathrm{H}\right] \mathbf{1}$ in a highly stereoselective manner. A racemic mixture of $\left[3-{ }^{2} \mathrm{H}\right] \mathbf{1}$ is generated from 2 in the presence of 4-OT under the same conditions. The sum of these observations indicates that the biological reaction of YwhB may involve a 1,3-keto-enol tautomerization of a diacid substrate while 4-OT might function almost exclusively as a 1,5keto-enol tautomerase in the meta-fission pathway.

\section{EXPERIMENTAL PROCEDURES}

\section{Materials}

All reagents, buffers, and solvents were obtained from Sigma-Aldrich Chemical Co. (St. Louis, MO) or Fisher Scientific Inc. (Pittsburgh, PA). The syntheses of 2-hydroxymuconate (2), 2hydroxy-2,4-pentadienoate (5), and 2-hydroxy-2,4-heptadiene-1,7-dioate (11) are described

\footnotetext{
${ }^{2}$ These compounds were examined as potential substrates for three reasons: they were synthetically available, their non-enzymatic properties and reactions have been well characterized in our laboratory, and the presence of key active sites groups (except Arg-39) in YwhB known to be critical for 4-OT activity suggested that they would be substrates. The absence of Arg-39 in the active site suggests that dienols with a neutral group at C-1 (e.g., a C-1 aldehyde or ester) might also be potential substrates. However, it will be necessary to synthesize and characterize the non-enzymatic properties of these compounds before such studies can be carried out.
} 
elsewhere $(4,7,20)$. Techniques for restriction enzyme digestion, ligation, transformation, and other standard molecular biology manipulations were based on methods described elsewhere (21). The sources for the components of Luria-Bertani (LB) media as well as the enzymes and reagents used in the molecular biology procedures are reported elsewhere $(18,21)$.

\section{General Methods}

Kinetic data were obtained on a Hewlett Packard 8452A Diode Array spectrophotometer or an Agilent 8453 UV-Visible spectrophotometer. The kinetic data were fitted by nonlinear regression data analysis using the Grafit program (Erithacus Software Ltd., Staines, U.K.) obtained from Sigma Chemical Co. Proteins were analyzed by tricine sodium dodecyl sulfatepolyacrylamide gel electrophoresis (SDS-PAGE) under denaturing conditions on 16-17.5\% gels on a vertical gel electrophoresis apparatus obtained from Bio-Rad (Hercules, CA) (22). Protein concentrations were determined using the method of Waddell (23). Nuclear magnetic resonance (NMR) spectra were recorded on a Varian UNITY-plus $300 \mathrm{MHz}$ spectrometer or a Varian Unity INOVA-500 spectrometer. Chemical shifts were referenced as noted below.

\section{Construction, Purification, and Characterization of the YwhB Mutants}

The experimental procedures used for the construction, expression, overproduction, purification, and mass spectral analysis of the P1A- and R11A-YwhB mutants are provided in the Supporting Information.

\section{Kinetic Characterization of YwhB and Mutants}

Kinetic runs were performed in $20 \mathrm{mM} \mathrm{NaH}_{2} \mathrm{PO}_{4}$ buffer, $\mathrm{pH} 7.3$, at $23{ }^{\circ} \mathrm{C}$. Stock solutions (50 $\mathrm{mM}$ ) of $\mathbf{2 , 7}$, and $\mathbf{8}$ were initially made up in ethanol, and diluted (with ethanol) to generate 5 $\mathrm{mM}$ and/or $10 \mathrm{mM}$ solutions. Solutions of 5 were made by diluting a stock solution $(153 \mathrm{mM})$ stored in ethanol at $-20^{\circ} \mathrm{C}$, to make $3.05 \mathrm{mM}$ and $30.5 \mathrm{mM}$ solutions. The tautomerization activities of YwhB were measured by monitoring the ketonization of the following substrates at the reported $\lambda_{\max }$ values using the corresponding $\varepsilon$ values, within the indicated concentration ranges, as follows: $\mathbf{2}\left(294 \mathrm{~nm}, \varepsilon=19,400 \mathrm{M}^{-1} \mathrm{~cm}^{-1}, 20-150 \mu \mathrm{M}\right), \mathbf{5}(266 \mathrm{~nm}, \varepsilon=12,100$ $\left.\mathrm{M}^{-1} \mathrm{~cm}^{-1}, 3-150 \mu \mathrm{M}\right), 7\left(288 \mathrm{~nm}, \varepsilon=18,000 \mathrm{M}^{-1} \mathrm{~cm}^{-1}, 10-150 \mu \mathrm{M}\right), 8(292 \mathrm{~nm}, \varepsilon=20,800$ $\left.\mathrm{M}^{-1} \mathrm{~cm}^{-1}, 10-150 \mu \mathrm{M}\right), \mathbf{1 1}\left(276 \mathrm{~nm}, \varepsilon=12,300 \mathrm{M}^{-1} \mathrm{~cm}^{-1}, 15-150 \mu \mathrm{M}\right)$, and as described elsewhere $(4,7,18,20,24)$. The ketonization of $\mathbf{2}$ to 3 was monitored at $236 \mathrm{~nm}(\varepsilon=6580$ $\left.\mathrm{M}^{-1} \mathrm{~cm}^{-1}\right)$ using a substrate concentration ranging from $30-600 \mu \mathrm{M}$, and $\mathrm{YwhB}(100 \mu \mathrm{L}$ of a $10.9 \mathrm{mg} / \mathrm{mL}$ solution) that had been equilibrated in buffer $(50 \mathrm{~mL})$ for at least $1 \mathrm{~h}$ prior to use (4). For experiments with 7 and 11, a quantity of YwhB ( $4 \mu \mathrm{L}$ of a $26 \mathrm{mg} / \mathrm{mL}$ solution for 7 and $120 \mu \mathrm{L}$ for 11$)$ was equilibrated in buffer $(40 \mathrm{~mL})$ for at least $1 \mathrm{~h}$ prior to use. For experiments with $\mathbf{2}, \mathbf{5}$ and $\mathbf{8}$, a quantity of $\mathrm{YwhB}(12.5 \mu \mathrm{L}$ of a $10.9 \mathrm{mg} / \mathrm{mL}$ solution, $2.5 \mu \mathrm{L}$ of a $29.7 \mathrm{mg} / \mathrm{mL}$ solution, $100 \mu \mathrm{L}$ of a $10.9 \mathrm{mg} / \mathrm{mL}$ solution, respectively) was equilibrated in buffer $(50 \mathrm{~mL})$ for at least an hour prior to use. For all experiments, aliquots $(1 \mathrm{~mL})$ were withdrawn and assayed for activity. Reactions were initiated by the addition of substrate. It was not possible to achieve saturation for some substrates due to the high $\varepsilon$ value coupled with the quantity of substrate required. In these cases, the $k_{\text {cat }}$ value reported in Table 1 is an estimate obtained from the Grafit program.

\section{The YwhB-Catalyzed Conversion of 7 to $\left[3-{ }^{2} \mathrm{H}\right] 9$ in $\mathrm{D}_{2} \mathrm{O}$ and Conversion of $[3-2 \mathrm{H}] 9$ to $\left[3-{ }^{2} \mathrm{H}\right]$ 13}

The stereochemical analysis of $\left[3-{ }^{2} \mathrm{H}\right] \mathbf{9}$ was carried out at room temperature by the series of reactions shown in Scheme 3 using protocols described elsewhere (24). A solution of 7 (4 mg, $24 \mu \mathrm{mol})$ dissolved in DMSO- $d_{6}(30 \mu \mathrm{L})$ was added to $100 \mathrm{mM} \mathrm{Na}_{2}[2 \mathrm{H}] \mathrm{PO}_{4}(0.6 \mathrm{~mL}, \mathrm{pD} 9.3)$ buffer made up in $\mathrm{D}_{2} \mathrm{O}$. Twenty individual reaction mixtures were made up. The addition of 7 (as the free acid) lowered the $\mathrm{pH}$ to $\sim 6.8$. Enzyme ( $15 \mu \mathrm{L}$ of a $1.5 \mathrm{mg} / \mathrm{mL}$ solution) was added 
to the individual reaction mixtures and the reactions were allowed to proceed for $1.5 \mathrm{~min}$ before they were quenched with $\mathrm{NaBH}_{4}$. The product, $\left[3-{ }^{2} \mathrm{H}\right] \mathbf{1 3}$, was isolated and purified as described (24) to give $77.5 \mathrm{mg}$ of the compound. The ${ }^{1} \mathrm{H}$ NMR spectrum corresponded to that previously reported (24).

\section{Conversion of $\left[3^{2} \mathrm{H}\right] 13$ to $(2 \mathrm{R}, 3 \mathrm{~S})-\left[3^{-2} \mathrm{H}\right]$ Malate (15)}

The conversion of $\left[3-{ }^{2} \mathrm{H}\right] \mathbf{1 3}$ to $\mathbf{1 4}$ (Scheme 3 ) was carried out by the ozonolysis of $\left[3-{ }^{2} \mathrm{H}\right] \mathbf{1 3}$ (and treatment of the product with $\mathrm{H}_{2} \mathrm{O}_{2}$ ) to generate 14 , which was purified by anion-exchange chromatography to afford $22.3 \mathrm{mg}$ of the compound. The $(2 S)$-isomer was removed by treating the diastereomeric mixture with malic enzyme as described (24). Subsequently, the (2R)isomer was purified by anion-exchange chromatography, yielding $8.7 \mathrm{mg}$ of $(2 R, 3 S)$ - and $(2 R, 3 R)-\left[3-{ }^{2} \mathrm{H}\right]$ malate (15). The ${ }^{1} \mathrm{H}$ NMR spectrum corresponded to that previously reported (24) and indicated that the $(2 R, 3 S)$-isomer of $\left[3-{ }^{2} \mathrm{H}\right]$ malate $(\mathbf{1 5})$ predominated by a ratio of $\sim 3: 1$.

\section{Conversion of 5 to $\left[{ }^{3}-{ }^{2} \mathrm{H}\right] 4$ in $\mathrm{D}_{\mathbf{2}} \mathrm{O}$ and Processing to $(2 \mathrm{R}, 3 \mathrm{~S})-[3-2 \mathrm{H}]$ Malate (15)}

The stereochemical analysis of $\left[3-{ }^{2} \mathrm{H}\right] \mathbf{4}$, generated by the incubation of $\mathrm{YwhB}$ and $\mathbf{5}$ in $\mathrm{D}_{2} \mathrm{O}$, was carried out by a modification of a literature procedure (24). The individual reactions (20 total) contained 5 (4 mg dissolved in $30 \mu \mathrm{L}$ of DMSO- $\left.d_{6}, 35 \mu \mathrm{mol}\right)$ and $\mathrm{YwhB}(1 \mu \mathrm{L}$ of a 3.4 $\mathrm{mg} / \mathrm{mL}$ solution) in $100 \mathrm{mM} \mathrm{Na}_{2}[2 \mathrm{H}] \mathrm{PO}_{4}\left(0.6 \mathrm{~mL}, \mathrm{pD}\right.$ 9.3) buffer made up in $\mathrm{D}_{2} \mathrm{O}$. The reaction mixtures were allowed to proceed for $1.75 \mathrm{~min}$ before they were quenched with $\mathrm{NaBH}_{4}$, combined, and purified to yield $26 \mathrm{mg}$ of [3-2H]16 (Scheme 4). Subsequently, $\left[3-{ }^{2} \mathrm{H}\right]$ 16 was processed to [3-D]14 as described elsewhere to yield $9.8 \mathrm{mg}$ of product (24). Treatment with malic enzyme yielded $\sim 1 \mathrm{mg}$ of $(2 R, 3 S)$ - and $(2 R, 3 R)-\left[3-{ }^{2} \mathrm{H}\right]$ malate $(\mathbf{1 5})$. The ${ }^{1} \mathrm{H}$ NMR spectrum corresponded to that previously reported (24) and indicated that the $(2 R, 3 S)$-isomer of $\left[3-{ }^{2} \mathrm{H}\right]$ malate $(\mathbf{1 5})$ predominated by a ratio of $\sim 4.4: 1$.

\section{YwhB-catalyzed Conversion of 2 to $\left[{ }^{3}-{ }^{2} \mathrm{H}\right] 1$ in $\mathrm{D}_{2} \mathrm{O}$ and Conversion of $[3-2 \mathrm{H}] 1$ to $\left[{ }^{2}{ }^{2} \mathrm{H}\right] 17$}

A solution of $2(4 \mathrm{mg}, 25 \mu \mathrm{mol})$ dissolved in DMSO- $d_{6}(30 \mu \mathrm{L})$ was added to $100 \mathrm{mM}$ $\mathrm{Na}_{2}[2 \mathrm{H}] \mathrm{PO}_{4}(0.6 \mathrm{~mL}, \mathrm{pD} 9.3)$ buffer made up in $\mathrm{D}_{2} \mathrm{O}$. Ten individual reaction mixtures were made up similarly. The addition of $\mathbf{2}$ (as the free acid) adjusted the $\mathrm{pH}$ of the individual reaction mixtures to $\sim 6.8$. Compound 2 had been previously dissolved in $\mathrm{CD}_{3} \mathrm{OD}$ and evaporated to dryness $(3 \times)$ in order to exchange the acidic protons for deuterons. The enzyme ( $25 \mu \mathrm{L}$ of a $20.7 \mathrm{mg} / \mathrm{mL}$ solution) was added to the individual reaction mixtures and the reactions were allowed to proceed for $1 \mathrm{~min}$ before they were quenched with $\mathrm{NaBH}_{4}(20 \mu \mathrm{L}$ of a $300 \mathrm{mg} / \mathrm{mL}$ solution in $100 \mathrm{mM} \mathrm{Na}_{2}[2 \mathrm{H}] \mathrm{PO}_{4}$ buffer, $\left.\mathrm{pH} \sim 9.3\right) .{ }^{1} \mathrm{H}$ NMR analysis of an individual reaction mixture indicated that the highest concentration of 1 was observed after 1 min. The reaction mixtures were combined after a 1-h incubation period with $\mathrm{NaBH}_{4}$, and the $\mathrm{pH}$ was adjusted to 6 with $\mathrm{H}_{3} \mathrm{PO}_{4}(8.5 \%)$ in order to destroy the excess $\mathrm{NaBH}_{4}$. Subsequently, the $\mathrm{pH}$ of the reaction mixture was adjusted to $\sim 8$ (using aliquots of a $1 \mathrm{M} \mathrm{NaOH}$ solution), and loaded onto an anion-exchange column (formate), as described elsewhere (24). The product $(37 \mathrm{mg}$ ) was isolated and purified as described (24), and identified as a mixture of $\left[3-{ }^{2} \mathrm{H}\right] \mathbf{1 7}(\sim 26 \mathrm{mg}$ as estimated by ${ }^{1} \mathrm{H}$ NMR spectroscopy) and the reduced product of $\mathbf{3}(\sim 11 \mathrm{mg})$. The ${ }^{1} \mathrm{H}$ NMR spectrum corresponded to that previously reported (24).

\section{Conversion of $\left[3^{-2} \mathrm{H}\right] 17$ to $(2 \mathrm{R}, 3 \mathrm{R})-\left[3-^{-2} \mathrm{H}\right]$ Malate (15)}

The conversion of $\left[3-{ }^{2} \mathrm{H}\right] \mathbf{1 7}$ to $\mathbf{1 5}$ (Scheme 5) was carried out using ozonolysis (and subsequent treatment of the product with $\mathrm{H}_{2} \mathrm{O}_{2}$ ) to generate $\left[3-{ }^{2} \mathrm{H}\right] 14$, which was purified by anionexchange chromatography, resulting in the isolation of $4.2 \mathrm{mg}$ of the compound. The (2S)isomer was removed by treating the diastereomeric mixture with malic enzyme as described (24). Subsequently, the ( $2 R$ )-isomer was purified by anion-exchange chromatography, yielding 
$0.7 \mathrm{mg}$ of $(2 R, 3 R)$ - and $(2 R, 3 S)-\left[3-{ }^{2} \mathrm{H}\right]$ malate $(\mathbf{1 5})$. The ${ }^{1} \mathrm{H}$ NMR spectrum corresponded to that previously reported $(24)$ and indicated that the $(2 R, 3 R)$-isomer of $\left[3-{ }^{2} \mathrm{H}\right]$ malate $(\mathbf{1 5})$ predominated by a ratio of $\sim 8: 1$.

The Conversion of 2 to $\left[3-{ }^{2} \mathrm{H}\right] 1$ in the presence of $4-\mathrm{OT}$ in $\mathrm{D}_{2} \mathrm{O}$ and Conversion of $\left[3^{2} \mathrm{H}\right] 1$ to (2R,3R)- and (2R,3S)-[3-2 $\mathrm{H}]$ Malate (15)

Twenty individual reaction mixtures were made up as follows. Each reaction mixture contained a solution of $2(4 \mathrm{mg}, 25 \mu \mathrm{mol})$ dissolved in DMSO- $d_{6}(30 \mu \mathrm{L})$ and added to $100 \mathrm{mM}$ $\mathrm{Na}_{2}[2 \mathrm{H}] \mathrm{PO}_{4}(0.6 \mathrm{~mL}, \mathrm{pD} 9.3)$ buffer made up in $\mathrm{D}_{2} \mathrm{O}$. The addition of 2 (as the free acid) lowered the $\mathrm{pH}$ to $\sim 6.8$. The crystalline $\mathbf{2}$ had previously been dissolved in $\mathrm{CD}_{3} \mathrm{OD}$ and evaporated to dryness repeatedly in order to exchange the acidic protons for deuterons. Subsequently, an aliquot $(100 \mu \mathrm{L})$ of a solution composed of 4-OT $(120 \mu \mathrm{L}$ of a $3 \mathrm{mg} / \mathrm{mL}$ solution in $20 \mathrm{mM} \mathrm{Na}\left[{ }^{2} \mathrm{H}_{2}\right] \mathrm{PO}_{4}$ buffer, $\left.\mathrm{pD} \sim 7.0\right)$ and $\mathrm{NaBH}_{4}(160 \mathrm{mg}$ dissolved in $1.88 \mathrm{~mL}$ of $100 \mathrm{mM} \mathrm{Na}_{2}\left[{ }^{2} \mathrm{H}\right] \mathrm{PO}_{4}$ buffer, $\mathrm{pH} \sim 9.3$ ) was added to each individual reaction mixture. The reaction mixtures were allowed to stand at room temperature overnight, combined, and processed according to the procedure described above for the $\mathrm{YwhB}$ reaction (using 2 ) to yield a mixture $\left(74 \mathrm{mg}\right.$ ) of $\left[3-{ }^{2} \mathrm{H}\right] \mathbf{1 7}$ and the reduced product of $\mathbf{3}$ (in a 1:2 ratio as assessed by ${ }^{1} \mathrm{H}$ NMR spectroscopy). Subsequently, the solid material was dissolved in $\sim 100 \mu \mathrm{L}$ of $\mathrm{CH}_{3} \mathrm{OH}$, and subjected to ozonolysis, as described above for YwhB. Purification by anion-exchange chromatography resulted in the recovery of $18.2 \mathrm{mg}$ of $\left[3-{ }^{2} \mathrm{H}\right] \mathbf{1 4}$. The addition of $\mathrm{CH}_{3} \mathrm{OH}$ improved the product yield of the ozonolysis step. The diastereomeric mixture was then treated with malic enzyme and the resulting $(2 R)$-isomer was purified by anion-exchange chromatography, yielding $5.8 \mathrm{mg}$ of $(2 R, 3 R)$ - and $(2 R, 3 S)-\left[3-{ }^{2} \mathrm{H}\right]$ malate (15). The ${ }^{1} \mathrm{H}$ NMR spectrum corresponded to that previously reported (24) and indicated that both the $(2 R, 3 R)$ and $(2 R, 3 S)$-isomers of $\left[3-{ }^{2} \mathrm{H}\right]$ malate $(\mathbf{1 5})$ had been obtained in comparable amounts.

Repeating the experiment gave the same result.

\section{RESULTS}

Construction, Expression, Overproduction, and Characterization of the YwhB Mutants

Two mutants of YwhB (P1A and R11A) were constructed by overlap extension PCR (25), overproduced in E. coli strain BL21(DE3)pLysS, and purified to $>95 \%$ homogeneity (as assessed by SDS-PAGE), using the protocol described for the wild type enzyme $(17,18)$. The purification protocol resulted in large quantities of both mutants $(20-40 \mathrm{mg} / \mathrm{L}$ culture). The DNA sequence encoding each mutant was confirmed by DNA sequencing. In addition, each purified mutant generates one major peak in a mass spectrum, which corresponds to the expected mass. These observations provide additional evidence that only the intended mutations had been introduced into the proteins and confirm that Pro-1 is not blocked by the initiating methionine.

\section{Kinetic Properties of YwhB}

The kinetic properties of YwhB were investigated using the monocarboxylated dienol, 5, two enols ( $\mathbf{7}$ and $\mathbf{8}$ ), and two dicarboxylated dienols ( $\mathbf{2}$ and $\mathbf{1 1})$. For the three dienol substrates, the rates for the formation of the corresponding $\beta, \gamma$-unsaturated ketones were measured. It was also possible to determine a rate for the formation of $\mathbf{3}$, the $\alpha, \beta$-unsaturated ketone, from 2 . However, the YwhB-catalyzed rates for the formation of the corresponding $\alpha, \beta$-isomers for 5 and $\mathbf{1 1}$ could not be accurately measured because they were similar to the non-enzymatic rates. The kinetic data are summarized in Table 1 .

Several trends emerge from the data. First, YwhB catalyzes a 1,3-keto-enol tautomerization reaction using all of these substrates although with different catalytic efficiencies $\left(k_{\mathrm{cat}} / K_{\mathrm{m}}\right.$ values ranging from $9.0 \times 103-4.6 \times 105 \mathrm{M}^{-1} \mathrm{~s}^{-1}$ ). Second, the highest catalytic efficiencies 
are observed for the monocarboxylated compounds $\mathbf{5}$ and $\mathbf{7}$, followed by the dicarboxylated compound 2 (showing a 3.5-fold decrease in $k_{\text {cat }} / K_{\mathrm{m}}$ ). Replacing the vinyl group of 5 with a phenyl group (i.e., 7) has little effect on $k_{\text {cat }}$ and $K_{\mathrm{m}}$. The addition of a second carboxylate group to 5 (i.e., 2), results in a 11.2-fold decrease in $k_{\text {cat }}$, as well as a 3.2-fold decrease in $K_{\mathrm{m}}$. The decrease in catalytic efficiency observed for $\mathbf{2}$ is primarily a reflection of the decrease in $k_{\text {cat }}$. Third, the addition of the hydroxyl group to 7 (i.e., 8 ) results in a 30-fold decrease in $k_{\text {cat }}$ as well as a 1.9-fold decrease in $K_{\mathrm{m}}$. The overall effect is a 16-fold decrease in the value of $k_{\text {cat }} / K_{\mathrm{m}}$. Finally, the addition of a carboxymethyl group to 5 (i.e., 11) results in a 37-fold decrease in $k_{\text {cat }}$, a 1.4-fold increase in $K_{\mathrm{m}}$, and an overall 51 -fold decrease in $k_{\text {cat }} / K_{\mathrm{m}}$.

The data in Table 1 also show that YwhB catalyzes a 1,5-keto-enol tautomerization reaction using $\mathbf{2}$, although not as efficiently as 4-OT. 4-OT catalyzes the conversion of $\mathbf{2}$ to $\mathbf{3}$ with a $k_{\text {cat }}=3500 \mathrm{~s}^{-1}$ and a $K_{\mathrm{m}}$ of $180 \mu \mathrm{M}$, resulting in an overall $k_{\mathrm{cat}} / K_{\mathrm{m}}$ of $1.9 \times 107 \mathrm{M}^{-1} \mathrm{~s}^{-1}$ (13). In comparison to 4-OT, YwhB shows a 135 -fold decrease in $k_{\text {cat }}$, a 5.2 increase in $K_{\mathrm{m}}$, and a 680 -fold decrease in $k_{\text {cat }} / K_{\mathrm{m}}$. Interestingly, the $K_{\mathrm{m}}$ value is 12 -fold higher than that measured for the 1,3-keto-enol tautomerization reaction. The difference may reflect less than optimal binding for $\mathbf{2}$ when it undergoes the 1,5-keto-enol tautomerization reaction.

\section{Kinetic Properties of the P1A and R11A Mutants of YwhB}

The P1A and R11A mutants of YwhB were constructed to determine the importance of these residues in the 1,3- and 1,5-keto-enol tautomerization reactions catalyzed by YwhB. The mutants were analyzed using $\mathbf{2}$ (determining the rate for the conversion to $\mathbf{1}$ and $\mathbf{3}$ ), $\mathbf{5}$, and $\mathbf{7}$, and the data are summarized in Tables 2 and 3. For $\mathbf{2}$, there was no detectable formation of $\mathbf{1}$ or 3 using either mutant. For $\mathbf{5}$, the P1A mutant showed a 45 -fold decrease in $k_{\text {cat }}$ and a 1.6fold decrease in $K_{\mathrm{m}}$, resulting in a $\sim 70$-fold decrease in $k_{\text {cat }} / K_{\mathrm{m}}$ (Table 2). Replacing Arg- 11 with an alanine has a profound effect on the activity. The R11A showed a $\sim 1900$-fold decrease in $k_{\text {cat }}$ and a 1.8 -fold decrease in $K_{\mathrm{m}}$, producing a 1022 -fold decrease in $k_{\text {cat }} / K_{\mathrm{m}}$ (Table 2). Similar results are observed for both mutants using 7 (Table 3). The P1A mutant showed a 104-fold decrease in $k_{\text {cat }}$ and a 1.4 -fold decrease in $K_{\mathrm{m}}$. This results in a $\sim 74$-fold decrease in $k_{\text {cat }} / K_{\mathrm{m}}$. The R11A showed a $\sim 2300$-fold decrease in $k_{\text {cat }}$ and a 3.7 -fold decrease in $K_{\mathrm{m}}$, producing a $\sim 610$-fold decrease in $k_{\text {cat }} / K_{\mathrm{m}}$.

\section{Stereochemical Analysis of the YwhB-catalyzed Formation of $\left[3^{-2} \mathrm{H}\right] 9$ from 7 in $\mathrm{D}_{2} \mathrm{O}$}

The stereochemical analysis of $\left[3-{ }^{2} \mathrm{H}\right] \mathbf{9}$ was carried out using a previously described protocol, which involves the chemical and enzymatic conversion of $\left[3-{ }^{2} \mathrm{H}\right] 9$ to the diastereomeric $\left[3-{ }^{2} \mathrm{H}\right]$ malate (14) (Scheme 3). The addition of YwhB to a buffered solution made up in $\mathrm{D}_{2} \mathrm{O}$ and containing 7 results in the ketonization of 7 to $\left[3-{ }^{2} \mathrm{H}\right] \mathbf{9}$. The subsequent addition of $\mathrm{NaBH}_{4}$ reduces $\left[3-{ }^{2} \mathrm{H}\right] \mathbf{9}$ to $\left[3-{ }^{2} \mathrm{H}\right] \mathbf{1 3}$, which is not susceptible to epimerization at the $\mathrm{C}-3$ position. The conversion of $\left[3-{ }^{2} \mathrm{H}\right] 13$ to $\left[3-{ }^{2} \mathrm{H}\right] 14$ is carried out by the ozonolysis of $\left[3-{ }^{2} \mathrm{H}\right]$ 13, followed by treatment of the ozonide with hydrogen peroxide (24). These reactions result in the formation of the $(2 R)$ - and $(2 S)$-isomers of $\left[3-{ }^{2} \mathrm{H}\right] \mathbf{1 4}$ because the $\mathrm{NaBH}_{4}$ reduction of $\left[3-{ }^{2} \mathrm{H}\right] \mathbf{9}$ is stereorandom. Incubation of $\left[3-{ }^{2} \mathrm{H}\right] \mathbf{1 4}$ with malic enzyme yields the $(2 R)$-isomer, which is analyzed by ${ }^{1} \mathrm{H}$ NMR spectroscopy.

Each diastereotopic proton at C-3 of the fully protio malate appears as a doublet of doublets at 2.33 and $2.63 \mathrm{ppm}$ in $\mathrm{D}_{2} \mathrm{O}$ (26). ( $\mathrm{In}_{\mathrm{CD}} \mathrm{OD}$, the signals are shifted downfield and appear at 2.62 and $2.78 \mathrm{ppm}$.) The stereospecific incorporation of a deuteron at C-3 results in the loss of one signal and the collapse of the remaining signal into a broadened doublet (27). The resonances for $(2 R)-\left[3-{ }^{2} \mathrm{H}\right]$ malate have been assigned by the reaction of maleate with maleate hydratase in $\mathrm{D}_{2} \mathrm{O}(27)$. The product of this reaction is $(2 R, 3 R)-\left[3-{ }^{2} \mathrm{H}\right]$ malate, and the resulting ${ }^{1} \mathrm{H}$ NMR spectrum shows the loss of the upfield signal $(2.33 \mathrm{ppm})$ and the presence of a downfield doublet (2.66 ppm). 
For the YwhB-catalyzed reaction (in $\mathrm{D}_{2} \mathrm{O}$ ) using 7 , the $1 \mathrm{H}$ NMR spectrum (recorded in $\mathrm{CD}_{3} \mathrm{OD}$ ) shows two major signals, one at $\sim 2.62$ (a broadened doublet of triplets) and one at $\sim 2.77 \mathrm{ppm}$ (a broadened multiplet) (Figure 1A) ${ }^{3}$. (The smaller coupling constant for the signal at $2.77 \mathrm{ppm}$ and the presence of protio malate does not permit resolution of the multiplet.) The signal at $2.62 \mathrm{ppm}$ corresponds to $(2 R, 3 S)-\left[3-{ }^{2} \mathrm{H}\right]$ malate $(\mathbf{1 5})$ and the signal at $2.77 \mathrm{ppm}$ corresponds to $(2 R, 3 R)-\left[3-{ }^{2} \mathrm{H}\right]$ malate. The value of the integral assigned to the $(2 R, 3 S)$ isomer is about 3-fold greater than that of the corresponding integral for the $(2 R, 3 R)$ isomer. Thus, the reaction is stereoselective and the $(2 R, 3 S)$ isomer predominates. The $S$ configuration at C-3 of $\mathbf{1 5}$ indicates that the stereochemistry at C-3 of $\mathbf{1 3}$ is $R$ because a phenyl group replaces the carboxylate group at C-4. On the basis of this assignment, $\mathrm{YwhB}$ catalyzes the ketonization of 7 to yield $(3 R)-\left[3-{ }^{2} \mathrm{H}\right] \mathbf{9}$, favoring the $R$-isomer by a ratio of $\sim 3: 1$.

\section{Stereochemical Analysis of the YwhB-catalyzed Formation of $\left[3-{ }^{2} \mathrm{H}\right] 4$ from 5}

The stereochemical analysis of $\left[3-{ }^{2} \mathrm{H}\right] \mathbf{4}$, generated by the YwhB-catalyzed ketonization of 5 in $\mathrm{D}_{2} \mathrm{O}$, was carried out as described above and elsewhere (24). Accordingly, $\left[3-{ }^{2} \mathrm{H}\right] \mathbf{4}$ was converted by the series of reactions shown in Scheme 4 to the $(2 R)$-isomer of $\left[3-{ }^{2} \mathrm{H}\right]$ malate, which was analyzed by ${ }^{1} \mathrm{H}$ NMR spectroscopy. The ${ }^{1} \mathrm{H}$ NMR spectrum (recorded in $\mathrm{CD}_{3} \mathrm{OD}$ ) shows the two characteristic signals at 2.61 (corresponding to $\left.(2 R, 3 S)-\left[3-{ }^{2} \mathrm{H}\right] 15\right)$ and $2.77 \mathrm{ppm}$ (corresponding to $\left.(2 R, 3 R)-\left[3-{ }^{2} \mathrm{H}\right] 15\right)$ (Figure 1B) ${ }^{3}$. The value of the integral assigned to the $(2 R, 3 S)$ isomer is about 4.4-fold greater than that of the corresponding integral for the ( $2 R$, $3 R)$ isomer. Again, the reaction is stereoselective and the $(2 R, 3 S)$ isomer predominates. The $S$ configuration at C-3 of $\mathbf{1 5}$ indicates that the stereochemistry at C-3 of $\mathbf{1 6}$ is $R$ because a double bond replaces the carboxylate group at $\mathrm{C}-4$. On the basis of this assignment, $\mathrm{YwhB}$ catalyzes the ketonization of 5 to produce $(3 R)-\left[3-{ }^{2} \mathrm{H}\right] \mathbf{4}$, favoring the $R$-isomer by a ratio of $\sim 4.4: 1$.

\section{Stereochemical Analysis of the YwhB-catalyzed Formation of $\left[3^{-2} \mathrm{H}\right] 1$ from 2}

A stereochemical analysis was also carried out on $\left[3-^{2} \mathrm{H}\right] \mathbf{1}$, generated from the YwhB-catalyzed ketonization of the diacid $\mathbf{2}$, using the series of reactions described elsewhere as shown in Scheme 5 (24). The ${ }^{1} \mathrm{H}$ NMR spectrum (recorded in $\mathrm{CD}_{3} \mathrm{OD}$ ) of the resulting $(2 R)$-isomer of $\left[3-{ }^{2} \mathrm{H}\right]$ malate shows major signals at $\sim 2.59$ and $\sim 2.77 \mathrm{ppm}$, but the broadened multiplet at 2.77 ppm is clearly the predominant one (Figure $2 \mathrm{~A})$. This signal corresponds to $(2 R, 3 R)-\left[3-{ }^{2} \mathrm{H}\right]$ malate, and indicates that $(2 R, 3 R)-\left[3{ }^{2} \mathrm{H}\right] \mathbf{1 5}$ is the predominant product of the reaction. The $R$ configuration at C-3 of $\mathbf{1 5}$ indicates that the stereochemistry at C-3 of $\mathbf{1 7}$ is $S$ because a double bond replaces the carboxylate group at $\mathrm{C}-4$. On the basis of this assignment, $\mathrm{YwhB}$ catalyzes the ketonization of $\mathbf{2}$ to $(3 S)-\left[3-{ }^{2} \mathrm{H}\right] \mathbf{1}$, favoring the $S$-isomer by a ratio of $\sim 8: 1$.

\section{Stereochemical Analysis of $\left[3^{2} \mathrm{H}\right] 1$ generated from 2 in the presence of 4-OT}

A stereochemical analysis of $\left[3-{ }^{2} \mathrm{H}\right] \mathbf{1}$, generated in an incubation mixture containing 4-OT and 2 in $\mathrm{D}_{2} \mathrm{O}$, was also carried out. Using the protocol described above and elsewhere (24), the $\left(2 R\right.$ )-isomer of $\left[3-{ }^{2} \mathrm{H}\right]$ malate was generated and analyzed by ${ }^{1} \mathrm{H}$ NMR spectroscopy (in $\mathrm{CD}_{3} \mathrm{OD}$ ). Integration of the doublet of triplets at 2.62 and the broadened multiplet at $2.78 \mathrm{ppm}$ showed that both the $(3 R)$ - and $(3 S)$-isomers were present in comparable amounts (within experimental error) indicating that the conversion of 2 to $\left[3-{ }^{2} \mathrm{H}\right] \mathbf{1}$, in $\mathrm{D}_{2} \mathrm{O}$, in the presence of 4-OT, is stereorandom (Figure 2B)3. Our ability to obtain highly stereoselectively labeled $\left[3-{ }^{2} \mathrm{H}\right]$ malate using YwhB and $\mathbf{2}$ under otherwise identical conditions suggests that this observation is not an artifact of the protocol. A repeat of the stereochemical analysis gave the same result.

\footnotetext{
${ }^{3}$ The smaller doublets at 2.64 and $2.80 \mathrm{ppm}$ correspond to the fully protio malate, which results from the presence of $\mathrm{H}_{2} \mathrm{O}$ in the reaction mixture.
} 


\section{DISCUSSION}

The tautomerase superfamily is a group of structurally homologous enzymes sharing a characteristic $\beta-\alpha-\beta$ building block and a catalytic Pro-1 (16,28-30). The 4-OT family, named for the first characterized enzyme in the family, is one of the five known families in this superfamily. 4-OT family members, including YwhB, are typically constructed from short sequences (61-84 amino acids) and are found throughout the microbial community (29). Only a handful of these family members have assigned functions $(29,30)$. The inability to assign functions for the majority of the family members precludes an understanding of this niche in microbial metabolism. Defining parameters for potential substrates may ultimately assist in the determination of biological functions.

Our initial interest in YwhB stemmed from two observations: it shared modest sequence identity, yet significant structural homology with 4-OT, and appeared to be "missing" only Arg-39, which is one of four residues known to be critical for 4-OT activity $(16,29)$. In YwhB, a valine residue occupies this position. Nonetheless, the similarities suggested two mechanistic possibilities. In one, YwhB functions as an isomerase/tautomerase using a mechanism that largely parallels that of 4-OT where another group takes the place of Arg-394. Alternatively, YwhB acts analogously to the R39 mutants of 4-OT (e.g., R39A or R39Q) (13). In either mechanism, Pro-1 serves as the catalytic base and Arg-11 interacts with a substrate carboxylate group and plays a role in binding and perhaps catalysis. This proposed mechanism is analogous to that of 4-OT where Pro-1 is the catalytic base and Arg-11 binds substrate through its interaction with the C-6 carboxylate group of $\mathbf{1}(12,13,31)$. This interaction also facilitates protonation at $\mathrm{C}-5$ (to form 3 ) because it draws electron density to the $\mathrm{C}-5$ position by resonance and inductive effects. Arg-39 interacts with the C-1 carboxylate group (of $\mathbf{1}$, in the context of Scheme 1) as well as the 2-keto group $(12,13)$. The latter interaction facilitates catalysis by polarizing the carbonyl group.

The kinetic assessment of YwhB using 2 shows that it behaves like the R39 mutants of 4-OT. YwhB catalyzes the conversion of $\mathbf{2}$ to 3 with a $k_{\text {cat }} / K_{\mathrm{m}}$ of $2.8 \times 104 \mathrm{M}^{-1} \mathrm{~s}^{-1}$, similar to the values measured for R39A-4-OT $\left(9.7 \times 10^{4} \mathrm{M}^{-1} \mathrm{~s}^{-1}\right)$ and R39Q-4-OT $\left(1.9 \times 10^{4} \mathrm{M}^{-1} \mathrm{~s}^{-1}\right)$ (13). These studies also showed that YwhB processed $\mathbf{2}$ to $\mathbf{1}$ preferentially before a slower formation of $\mathbf{3}$. Further kinetic characterization using 5, 7, 8, and $\mathbf{1 1}$ showed that $\mathrm{YwhB}$ is a highly efficient 1,3-keto-enol tautomerase, but clearly not a 1,5-keto-enol tautomerase using these four dienols ${ }^{5}$. A possible explanation for the different reactions is different binding modes. In one scenario, the C-6 carboxylate group of 2 may interact with Arg-11 and the C-1 carboxylate group may interact with an unknown group. Alternatively, the $\mathrm{C}-1$ carboxylate groups of 5, 7, 8, and 11 may interact with Arg-11 in a reverse binding mode.

The mutagenesis results implicate Pro- 1 and Arg-11 as critical residues in the reactions using $\mathbf{2}, \mathbf{5}$, and $\mathbf{7}$. Replacing either residue with alanine eliminates the ability of YwhB to carry out a 1,3- or 1,5-keto-enol tautomerization reaction using $\mathbf{2}$ and diminishes its ability to carry out a 1,3-keto-enol tautomerization reaction using $\mathbf{5}$ or $\mathbf{7}$. Previous work on P1 mutants in the tautomerase superfamily suggested that the P1A-mutant of $\mathrm{YwhB}$ would retain some activity because it still has an $\alpha$-amino group that can function as a catalytic base $(11,32)$. For example, the P1A mutant of 4-OT catalyzes the conversion of $\mathbf{2}$ to $\mathbf{3}$ with only a $\sim 22$-fold decrease in $k_{\text {cat }} / K_{\mathrm{m}}$ from that observed for the wild type reaction (11). The decreased activity of the 4-OT mutant was attributed to the lowered basicity of the primary amine and the increased flexibility of the alanyl nitrogen, which results in sub-optimal positioning of the base. The reduced activity of P1A-YwhB using 5 and $\mathbf{7}$ can likewise be explained by the lowered basicity and increased

\footnotetext{
${ }^{4}$ The unliganded crystal structure does not suggest an obvious candidate to take the place of Arg-39(16).

${ }^{5}$ It is not known if R39A- and R39Q-4-OT behave similarly, but the possibility is currently being examined.
} 
flexibility of the alanyl nitrogen. The complete loss of activity for P1A-YwhB using 2 suggests that the two reactions (i.e., the 1,3- or 1,5-keto-enol tautomerization reactions) are more sensitive to the base change, and it may be that Ala-1 is no longer able to access C-3 or C-5.

In contrast, the R11A-YwhB reactions are completely inactive or severely compromised. The absence of activity using $\mathbf{2}$ and the significantly decreased $k_{\text {cat }}$ values and relatively unchanged $K_{\mathrm{m}}$ values for 5 and $\mathbf{7}$ suggest that Arg-11 plays primarily a catalytic role in these reactions. For the 1,5-keto-enol tautomerization reaction using 2, the absence of Arg-11 may no longer favor the attraction of electron density to C-5 (13). For protonation at C-3, the absence of the positively charged arginine may destabilize the developing carbanionic character of the intermediate after deprotonation of the 2-hydroxyl group. Alternatively, in all three reactions, changing Arg-11 could affect the $\mathrm{p} K_{\mathrm{a}}$ of Pro- 1 or the positioning of another catalytic group.

The stereochemical analysis of YwhB (using 2, 5, and 7) suggests that the mono- and diacids bind in different orientations in the active site. The YwhB-catalyzed reactions using the monoacids 5 and 7 are stereoselective with the $3 R$-isomers predominating (Table 4 ). In contrast, the YwhB-catalyzed conversion of diacid $\mathbf{2}$ to $\mathbf{1}$ is highly stereoselective, with the $3 S$-isomer predominating by a ratio of $\sim 8: 1$. The stereochemical results could be governed by the interactions of the substrate carboxylate groups, as follows. For the monoacids, the $\mathrm{C}-1$ carboxylate groups of $\mathbf{5}$ and $\mathbf{7}$ might interact with Arg-11 such that the proton is delivered primarily to the $r e$ face to produce the $3 R$-isomers. For the diacid, the C- 6 carboxylate group of 2 could also interact with Arg-11, but this interaction would now result in the proton being delivered to the si face to produce the $3 S$-isomer. This binding mode may also allow YwhB to carry out both a 1,3- and a 1,5-keto-enol tautomerization reaction, which is only observed with 2. Moreover, the high degree of stereoselectivity observed for the YwhB-catalyzed reaction using 2 suggests that the biological activity may involve a 1,3-keto-enol tautomerization reaction on a substrate with two carboxylate groups. This proposal is supported by the high $k_{\text {cat }} / K_{\mathrm{m}}$ values observed for the 1,3-keto-enol tautomerization reactions $\left(\sim 105 \mathrm{M}^{-1} \mathrm{~s}^{-1}\right)$.

The stereochemical analysis of YwhB provides an explanation for previous stereochemical studies of 4-OT using mono- and diacid substrates where two arginine residues (Arg-11 and Arg-39) are present. 4-OT processes 5 to $\left[3-{ }^{2} \mathrm{H}\right] \mathbf{4}$ in ${ }^{2} \mathrm{H}_{2} \mathrm{O}$, but produces only a slight excess of the (3R)-isomer (1.7:1) (Table 4) (7). The R11A mutant of 4-OT produces the ( $3 R$ )-isomer of $\left[3-{ }^{2} \mathrm{H}\right] \mathbf{4}$ (from 5 in $\mathrm{D}_{2} \mathrm{O}$ ), but in a much higher ratio (5:1) (13), and one that is similar to that observed for the YwhB reaction ( 4.4:1). Taken together, these observations suggest that 5 binds in two orientations in 4-OT. In one orientation, the $\mathrm{C}-1$ carboxylate group might interact with Arg-11 while in the other orientation it might interact with Arg-39. The 1.7:1 excess of the $3 R$-isomer suggests that one of these orientations is only slightly favored, but removing Arg-11 significantly increases the preference for one orientation. The stereochemical results observed for the 4-OT-catalyzed conversion of $\mathbf{1 1}$ to $\mathbf{1 2}$ (in $\mathrm{D}_{2} \mathrm{O}$ ) are consistent with this analysis in that this reaction results in a 2:1 mixture with the $3 R$-isomer predominating (31). The additional carboxymethyl group at C-5 in $\mathbf{1 1}$ may favor one binding mode over the other due to the bulk and charge of the carboxymethyl group.

The highly stereoselective ketonization of $\mathbf{2}$ to $\mathbf{1}$ (in $\mathrm{D}_{2} \mathrm{O}$ ) by $\mathrm{YwhB}$ has a major implication for the 4-OT-catalyzed reaction. Kinetic and stereochemical studies using $\mathbf{2 , 5}$, and $\mathbf{1 1}$ led to the proposed 4-OT reaction shown in Scheme 1. In the kinetic studies, it was found that 4-OT produced $\mathbf{3}$ faster when using a mixture of $\mathbf{1}$ and $\mathbf{2}$ (as substrate) as opposed to using $\mathbf{2}$ alone as substrate (4). The stereochemical studies showed that the conversion of $\mathbf{2}$ to $\mathbf{3}$ in $\mathrm{D}_{2} \mathrm{O}$ was highly stereoselective, producing $(5 \mathrm{~S})-5\left[{ }^{2} \mathrm{H}\right] \mathbf{3}(6)$, whereas the conversion of the monoacid 5 to 4 was stereoselective, (preferring the $3 R$-isomer by a ratio of 1.7 to 1 ) (7). It was inferred from this latter observation that the 4-OT-catalyzed conversion of the diacid $\mathbf{2}$ to $\mathbf{1}$ (in $\mathrm{D}_{2} \mathrm{O}$ ) would also generate the $3 R$-isomer $\left\{\right.$ i.e., $\left.(3 R)-\left[3-{ }^{2} \mathrm{H}\right] \mathbf{1}\right\}$ with a high degree of stereoselectivity 
because the two carboxylate groups would firmly anchor the substrate at the active site (7). The combined stereochemical observations for $\mathbf{2}$ to $\mathbf{3}$ and $\mathbf{5}$ to $\mathbf{4}$ implied that 4-OT catalyzed a suprafacial, 1,3-allylic rearrangement of $\mathbf{1}$ to $\mathbf{3}$. The overall stereochemical course is consistent with a so-called one base mechanism where Pro-1 was eventually identified as the single base (33).

It has now been determined that a racemic mixture of $\left[3-{ }^{2} \mathrm{H}\right] \mathbf{1}$ results when 4-OT is incubated with 2 in $\mathrm{D}_{2} \mathrm{O}$. Such a result has been previously observed but was thought to be an artifact due to an inability to trap $\left[3-{ }^{2} \mathrm{H}\right] \mathbf{1}$ before it underwent a rapid chemical and enzymatic ketonization to $\left[3-{ }^{2} \mathrm{H}\right] 2(7,31)$. The work with YwhB indicates that the labeled species can be trapped and the stereochemistry assigned. Since stereospecificity is characteristic of an enzyme-catalyzed reaction, the resulting racemic mixture of $\left[3{ }^{2} \mathrm{H}\right] \mathbf{1}$ suggests that the conversion of $\mathbf{1}$ and $\mathbf{2}$ may not be enzyme-catalyzed (34). This observation could further suggest that 4-OT does not catalyze a 1,3-allylic rearrangement of $\mathbf{1}$ to $\mathbf{3}$, but instead, may simply catalyze the conversion of $\mathbf{2}$ to $\mathbf{3}$ (Scheme 6) $(3,35)$.

The proposed 4-OT-catalyzed 1,3-allylic rearrangement of $\mathbf{1}$ to $\mathbf{3}$ could still be salvaged" if it can be demonstrated unequivocally that 4-OT enhances the rate of formation of $\mathbf{1}$ from $\mathbf{2}$. If a rate acceleration is observed, then one possible explanation for the stereochemical results is that 4-OT binds 2 in either of two orientations. The 1,3-enol-keto tautomerization occurs in both orientations such that Pro- 1 transfers the enol proton (or deuteron) of 2 to the re or si face of $\mathrm{C}-3$ and generates a racemic mixture (in $\mathrm{D}_{2} \mathrm{O}$ ). In contrast, the 1,5-enol-keto tautomerization and 1,3-allylic rearrangement may only occur in one of these orientations. As a result, in $\mathrm{D}_{2} \mathrm{O}$, a deuteron is incorporated with a high degree of stereoselectivity at C-5. Although the appropriate kinetic experiments will be pursued, they are complicated by the fact that 4-OT converts $\mathbf{2}$ to $\mathbf{3}$ near the diffusion control limit $(10,13)$.

In lieu of these results, it is interesting to note that 4-OT functions somewhat promiscuously, and accelerates the partitioning of various dienols (e.g., 5 and 11) to the $\beta, \gamma$-unsaturated ketones, stereoselectively, before a slower conversion to their $\alpha, \beta$-unsaturated isomers. There are two explanations for this behavior. 4-OT likely encounters different dienols in the degradation of various aromatic compounds and the promiscuous binding enables their accommodation. It is also possible that the 1,3-keto-enol tautomerase of 4-OT is a vestigial activity and/or plays a "rescue" role by converting $\beta, \gamma$-unsaturated ketones (e.g., 4) to dienols (e.g., 5) if the dienol undergoes a non-enzymatic ketonization to 4 . The YwhB studies have provided valuable clues into its biological role and new insights into the 4-OT mechanism. The future delineation of similarities and differences will ultimately shed light on the structural basis for the 1,3- and the 1,5-keto-enol tautomerization reactions and perhaps a biological rationale.

\section{Supplementary Material}

Refer to Web version on PubMed Central for supplementary material.

\section{Acknowledgements}

Electrospray ionization (ESI) mass spectrometry was performed by the Analytical Instrumentation Facility Core (College of Pharmacy, The University of Texas at Austin) supported by Center grant ES07784. We also thank Steve D. Sorey (Department of Chemistry and Biochemistry, The University of Texas) for his expert assistance in acquiring the NMR spectra. 


\section{References}

1. Harayama S, Lehrbach PL, Timmis KN. Transposon mutagenesis analysis of meta-cleavage pathway operon genes of the TOL plasmid of Pseudomonas putida mt-2. J Bacteriol 1984;160:251-255. [PubMed: 6090417]

2. Harayama S, Rekik M, Ngai KL, Ornston LN. Physically associated enzymes produce and metabolize 2-hydroxy-2,4-dienoate, a chemically unstable intermediate formed in catechol metabolism via meta cleavage in Pseudomonas putida. J Bacteriol 1989;171:6251-6258. [PubMed: 2681159]

3. Dagley, S. Pathways for the utilization of organic growth substrates. In: Ornston, LN.; Sokatch, JR., editors. The Bacteria: A Treatise on Structure and Function. Academic Press; New York: 1978. p. 305-388.

4. Whitman CP, Aird BA, Gillespie WR, Stolowich NJ. Chemical and enzymatic ketonization of 2hydroxymuconate, a conjugated enol. J Am Chem Soc 1991;113:3154-3162.

5. Chen LH, Kenyon GL, Curtin F, Harayama S, Bembenek ME, Hajipour G, Whitman CP. 4Oxalocrotonate tautomerase, an enzyme composed of 62 amino acid residues per monomer. J Biol Chem 1992;267:17716-17721. [PubMed: 1339435]

6. Whitman CP, Hajipour G, Watson RJ, Johnson WH Jr, Bembenek ME, Stolowich NJ. Stereospecific ketonization of 2-hydroxymuconate by 4-oxalocrotonate tautomerase and 5-(carboxymethyl)-2hydroxymuconate isomerase. J Am Chem Soc 1992;114:10104-10110.

7. Lian H, Whitman CP. Ketonization of 2-hydroxy-2,4-pentadienoate by 4-oxalocrotonate tautomerase: implications for the stereochemical course and the mechanism. J Am Chem Soc 1993;115:7978-7984.

8. Subramanya HS, Roper DI, Dauter Z, Dodson EJ, Davies GJ, Wilson KS, Wigley DB. Enzymatic ketonization of 2-hydroxymuconate: specificity and mechanism investigated by the crystal structures of two isomerases. Biochemistry 1996;35:792-802. [PubMed: 8547259]

9. Stivers JT, Abeygunawardana C, Mildvan AS, Hajipour G, Whitman CP, Chen LH. Catalytic role of the amino-terminal proline in 4-oxalocrotonate tautomerase: affinity labeling and heteronuclear NMR studies. Biochemistry 1996;35:803-813. [PubMed: 8547260]

10. Stivers JT, Abeygunawardana Mildvan AS, Hajipour G, Whitman CP. 4-Oxalocrotonate tautomerase: $\mathrm{pH}$ dependences of catalysis and $\mathrm{p} K_{\mathrm{a}}$ values of active site residues. Biochemistry 1996;35:814-823. [PubMed: 8547261]

11. Czerwinski RM, Johnson WH Jr, Whitman CP, Harris TK, Abeygunawardana C, Mildvan AS. Kinetic and structural effects of mutations of the catalytic amino-terminal proline in 4-oxalocrotonate tautomerase. Biochemistry 1997;36:14551-14560. [PubMed: 9398173]

12. Taylor AB, Czerwinski RM, Johnson WH Jr, Whitman CP, Hackert ML. Crystal structure of 4oxalocrotonate tautomerase inactivated by 2-oxo-3-pentynoate at $2.4 \AA$ resolution: analysis and implications for the mechanism of inactivation and catalysis. Biochemistry 1998;37:14692-14700. [PubMed: 9778344]

13. Harris TK, Czerwinski RM, Johnson WH Jr, Legler PM, Abeygunawardana C, Massiah MA, Stivers JT, Whitman CP, Mildvan AS. Kinetic, stereochemical, and structural effects of mutations of the active site arginine residues in 4-oxalocrotonate tautomerase. Biochemistry 1999;38:12343-12357. [PubMed: 10493802]

14. Czerwinski RM, Harris TK, Johnson WH Jr, Legler PM, Stivers JT, Mildvan AS, Whitman CP. Effects of mutations of the active site arginine residues in 4-oxalocrotonate tautomerase on the $\mathrm{p} K_{\mathrm{a}}$ values of active site residues and on the $\mathrm{pH}$ dependence of catalysis. Biochemistry 1999;38:1235812366. [PubMed: 10493803]

15. Czerwinski RM, Harris TK, Massiah MA, Mildvan AS, Whitman CP. The structural basis for the perturbed $\mathrm{p} K_{\mathrm{a}}$ of the catalytic base in 4-oxalocrotonate tautomerase: kinetic and structural effects of mutations of Phe-50. Biochemistry 2001;40:1984-1995. [PubMed: 11329265]

16. Whitman CP. The 4-oxalocrotonate tautomerase family of enzymes: how nature makes new enzymes using a $\beta-\alpha-\beta$ structural motif. Arch Biochem Biophys 2002;402:1-13. [PubMed: 12051677]

17. Wang SC, Johnson WH Jr, Whitman CP. The 4-oxalocrotonate tautomerase- and YwhB-catalyzed hydration of $3 E$-haloacrylates: implications for the evolution of new enzymatic activities. J Am Chem Soc 2003;125:14282-14283. [PubMed: 14624569] 
18. Wang SC, Johnson WH Jr, Czerwinski RM, Whitman CP. Reactions of 4-oxalocrotonate tautomerase and YwhB with 3-halopropiolic acids: analysis and implications. Biochemistry 2004;43:748-758. [PubMed: 14730980]

19. Johnson WH Jr, Wang SC, Stanley TM, Czerwinski RM, Almrud JJ, Poelarends GJ, Murzin AG, Whitman CP. 4-Oxalocrotonate tautomerase, its homologue YwhB, and active vinylpyruvate hydratase: synthesis and evaluation of 2-fluoro substrate analogs. Biochemistry 2004;43:1049010501. [PubMed: 15301547]

20. Burks EA, Johnson WH Jr, Whitman CP. Stereochemical and isotopic labeling studies of 2-oxohept-4-ene-1,7-dioate hydratase: evidence for an enzyme-catalyzed ketonization step in the hydration reaction. J Am Chem Soc 1998;120:7665-7675.

21. Sambrook, J.; Fritsch, EF.; Maniatis, T. Molecular Cloning: A Laboratory Manual. 2. Cold Spring Harbor Laboratory; Cold Spring Harbor, NY: 1989.

22. Laemmli UK. Cleavage of structural proteins during the assembly of the head of bacteriophage T4. Nature 1970;227:680-685. [PubMed: 5432063]

23. Waddell WJ. A simple ultraviolet spectrophotometric method for the determination of protein. J Lab Clin Med 1956;48:311-314. [PubMed: 13346201]

24. Johnson WH Jr, Czerwinski RM, Stamps SL, Whitman CP. A kinetic and stereochemical investigation of the role of lysine-32 in the phenylpyruvate tautomerase activity catalyzed by macrophage migration inhibitory factor. Biochemistry 1999;38:16024-16033. [PubMed: 10625471]

25. Ho SN, Hunt HD, Horton RM, Pullen JK, Pease LR. Site-directed mutagenesis by overlap extension using the polymerase chain reaction. Gene 1989;77:51-59. [PubMed: 2744487]

26. Gawron O, Glaid AJ, Fondy TP. Stereochemistry of Krebs' cycle hydrations and related reactions. J Am Chem Soc 1961;83:3634-3640.

27. Englard S, Britten JS, Listowsky I. Stereochemical course of the maleate hydratase reaction. J Biol Chem 1967;242:2255-2259. [PubMed: 6022871]

28. Murzin AG. Structural classification of proteins: new superfamilies. Curr Opin Struct Biol 1996;6:386-394. [PubMed: 8804825]

29. Almrud JJ, Kern AD, Wang SC, Czerwinski RM, Johnson WH Jr, Murzin AG, Hackert ML, Whitman $\mathrm{CP}$. The crystal structure of $\mathrm{YdcE}$, a 4-oxalocrotonate tautomerase homologue from Escherichia coli, confirms the structural basis for oligomer diversity. Biochemistry 2002;41:12010-12024. [PubMed: 12356301]

30. Poelarends GJ, Whitman CP. Evolution of enzymatic activity in the tautomerase superfamily: mechanistic and structural studies of the 1,3-dichloropropene catabolic enzymes. Bioorg Chem 2004;32:376-92. [PubMed: 15381403]

31. Lian H, Czerwinski RM, Stanley TM, Johnson WH Jr, Watson RJ, Whitman CP. The contribution of the substrate's carboxylate group to the mechanism of 4-oxalocrotonate tautomerase. Bioorg Chem 1998;26:141-156.

32. Lubetsky J, Swope M, Dealwis C, Blake P, Lolis E. Pro-1 of macrophage migration inhibitory factor functions as a catalytic base in the phenylpyruvate tautomerase activity. Biochemistry 1999;38:73467354. [PubMed: 10353846]

33. Hanson KR, Rose IA. Interpretations of enzyme reaction stereospecificity. Acc Chem Res 1975;8:110.

34. Retey, J.; Robinson, JA. The mechanistic basis of stereospecificity. In: Ebel, HF., editor. Stereospecificity in Organic Chemistry and Enzymology. 13. Verlag Chemie; Weinheim, Germany: 1982. p. 17-51.

35. Sala-Trepat JM, Evans WC. The meta cleavage of catechol by Azotobacter species. 4-oxalocrotonate pathway. Eur J Biochem 1971;20:400-413. [PubMed: 4325686] 

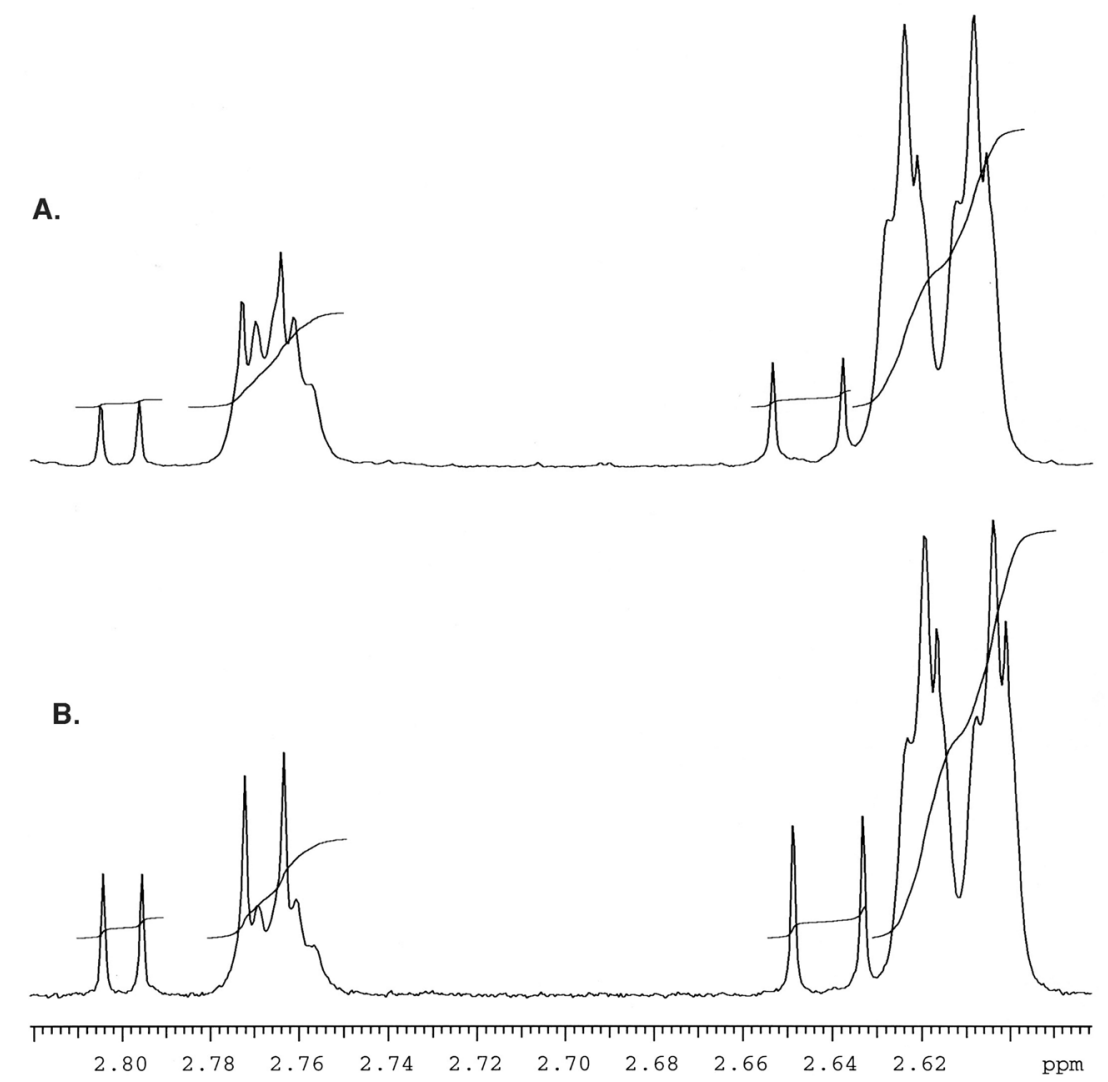

Figure 1.

Partial ${ }^{1} \mathrm{H}$ NMR spectra $\left(500 \mathrm{MHz}, \mathrm{CD}_{3} \mathrm{OD}\right)$ of the $(2 R)-\left[3-{ }^{2} \mathrm{H}\right]$ malate isolated in the stereochemical analysis of the YwhB-catalyzed reactions using (A) 7 as substrate and (B) 5 as substrate. In both spectra, the broadened doublet of triplets (centered at $\sim 2.62$ ) is the predominant signal. The smaller and sharper doublets $(2.64 \mathrm{ppm}$ and $2.80 \mathrm{ppm})$ correspond to the fully protio malate. 


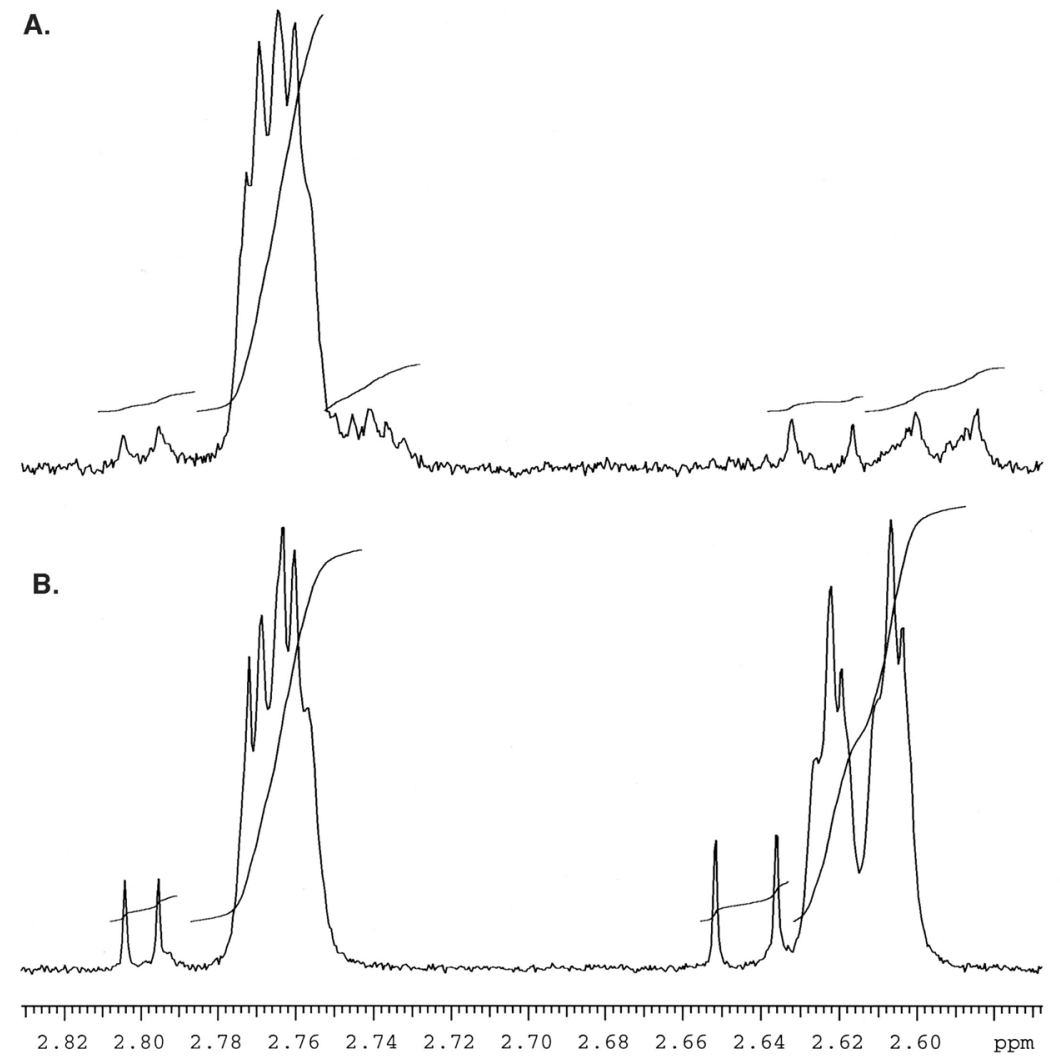

Figure 2.

Partial ${ }^{1} \mathrm{H} N M R$ spectra $\left(500 \mathrm{MHz}, \mathrm{CD}_{3} \mathrm{OD}\right)$ of the $(2 R)-\left[3-{ }^{2} \mathrm{H}\right]$ malate isolated from the YwhBcatalyzed reaction using 2 and the incubation mixture containing 2 and 4-OT. (A) The broadened multiplet is the major signal present and corresponds to $(2 R, 3 R)-\left[3-{ }^{2} \mathrm{H}\right] \mathrm{malate}$. (B) The broadened multiplet $(2.76 \mathrm{ppm})$ and a broadened doublet of triplets $(2.61 \mathrm{ppm})$ are the major signals present. Integration of the signals indicates that $(2 R, 3 R)-$ and $(2 R, 3 S)-\left[3-{ }^{2} \mathrm{H}\right]$ malate are present in comparable amounts. Signals corresponding to the fully protio malate are also present at 2.64 and $2.80 \mathrm{ppm}$. 

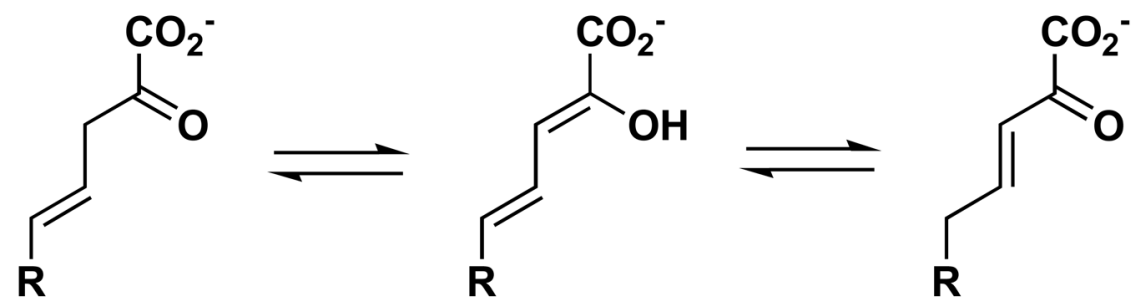

$$
\text { 1: } \mathrm{R}=\mathrm{CO}_{2}^{-}
$$

2: $\mathrm{R}=\mathrm{CO}_{2}^{-}$

5: $R=H$

3: $\mathrm{R}=\mathrm{CO}_{2}^{-}$

6: $R=H$

Scheme 1. 
<smiles>[R]c1ccc(C=C(O)C(=O)OC(=O)C(=O)OCc2ccc([R])cc2)cc1</smiles><smiles>[R]C=CC=C(O)C(=O)O[Na]</smiles><smiles>[R]C=CCC(=O)C(=O)[O-]</smiles>

$$
\text { 7: } \mathbf{R}=\mathrm{H}
$$$$
\text { 9: } \mathbf{R}=\mathrm{H}
$$

8: $\mathrm{R}=\mathrm{OH}$ 10: $\mathrm{R}=\mathrm{OH}$

11: $\mathrm{R}=\mathrm{CH}_{2} \mathrm{CO}_{2}^{-}$

12: $\mathrm{R}=\mathrm{CH}_{2} \mathrm{CO}_{2}^{-}$

Scheme 2. 


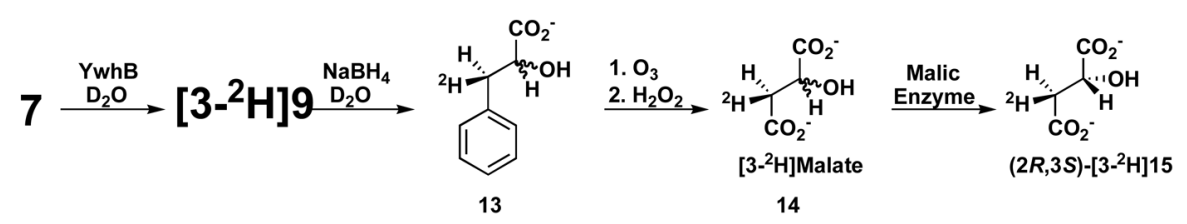

Scheme 3. 


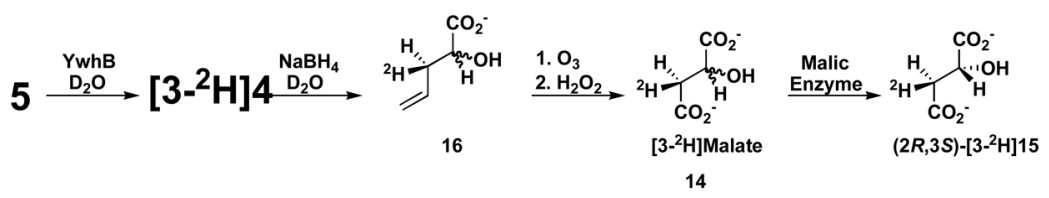

Scheme 4.

Biochemistry. Author manuscript; available in PMC 2008 October 23. 


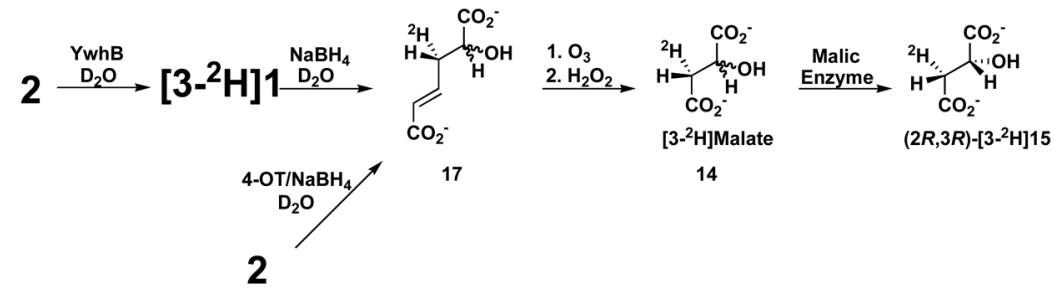

Scheme 5. 


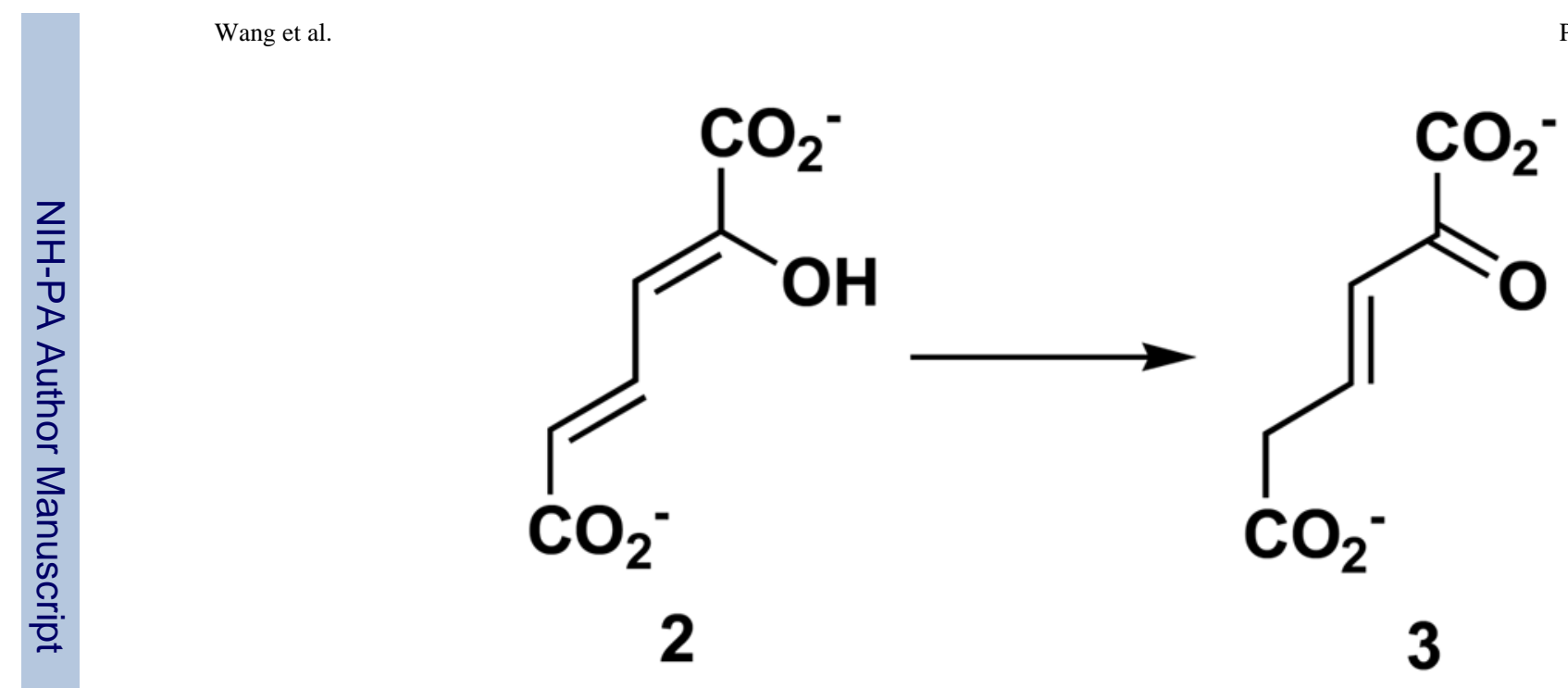

Scheme 6. 
Table 1

Kinetic Parameters for YwhB Using Enol and Dienol Substrates ${ }^{a}$

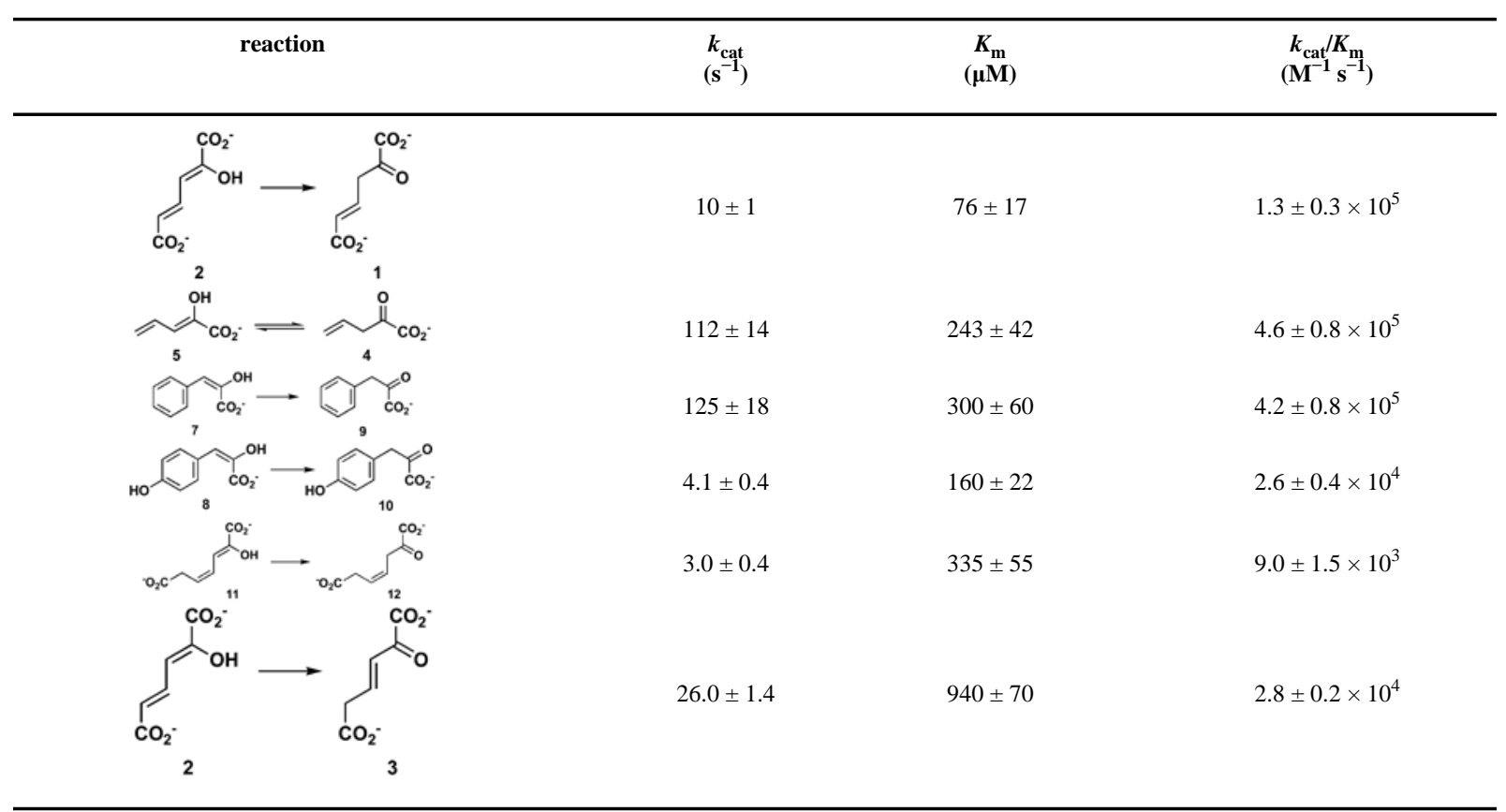

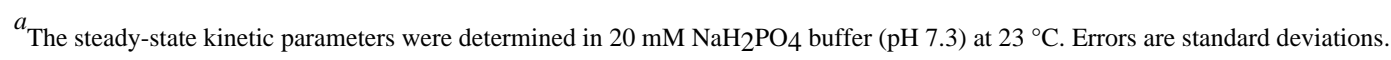




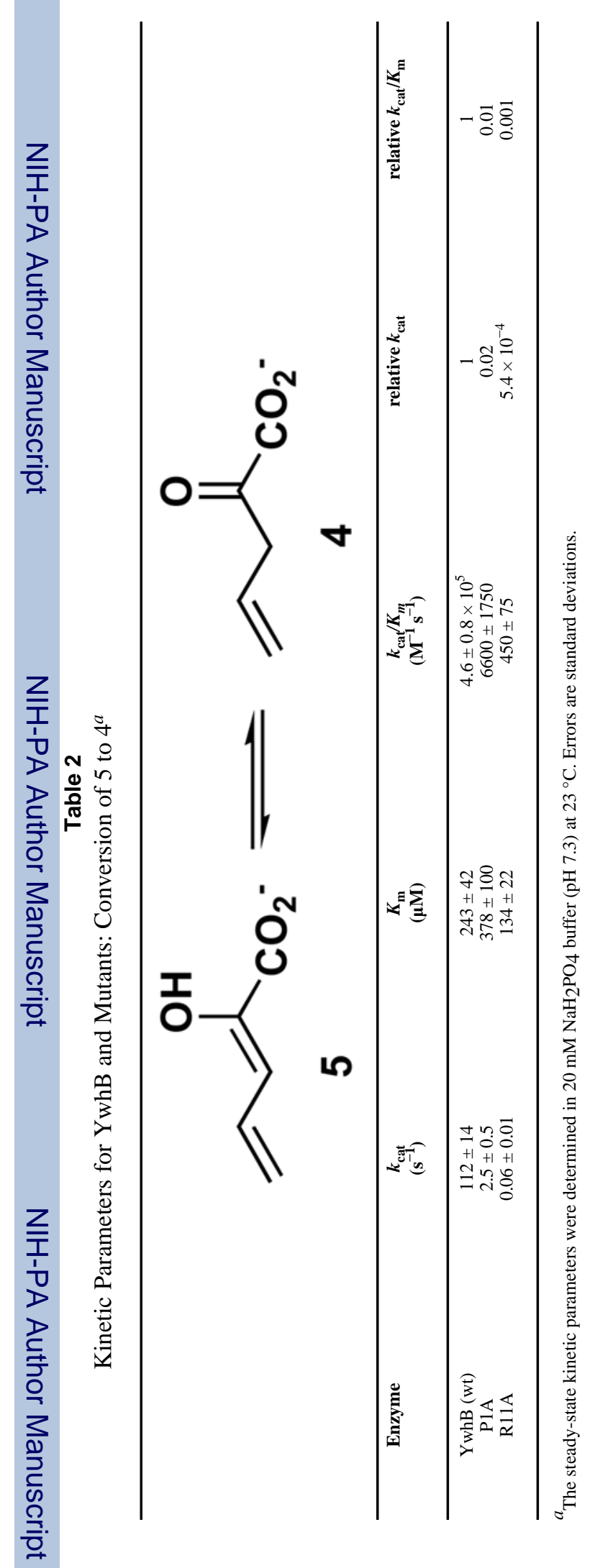


Wang et al.

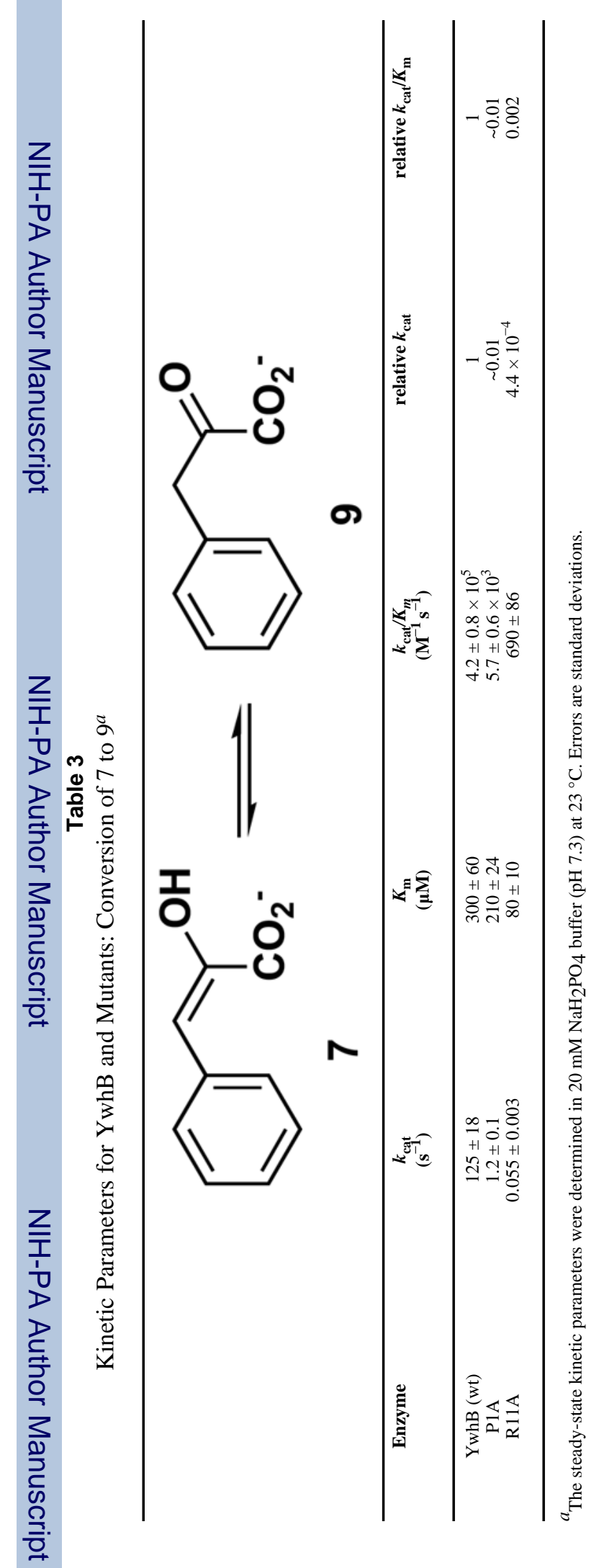


Table 4

Stereochemical Consequences of Reactions in the Presence of YwhB, 4-OT, and R11A-4-OT in $\mathrm{D}_{2} \mathrm{O}$.

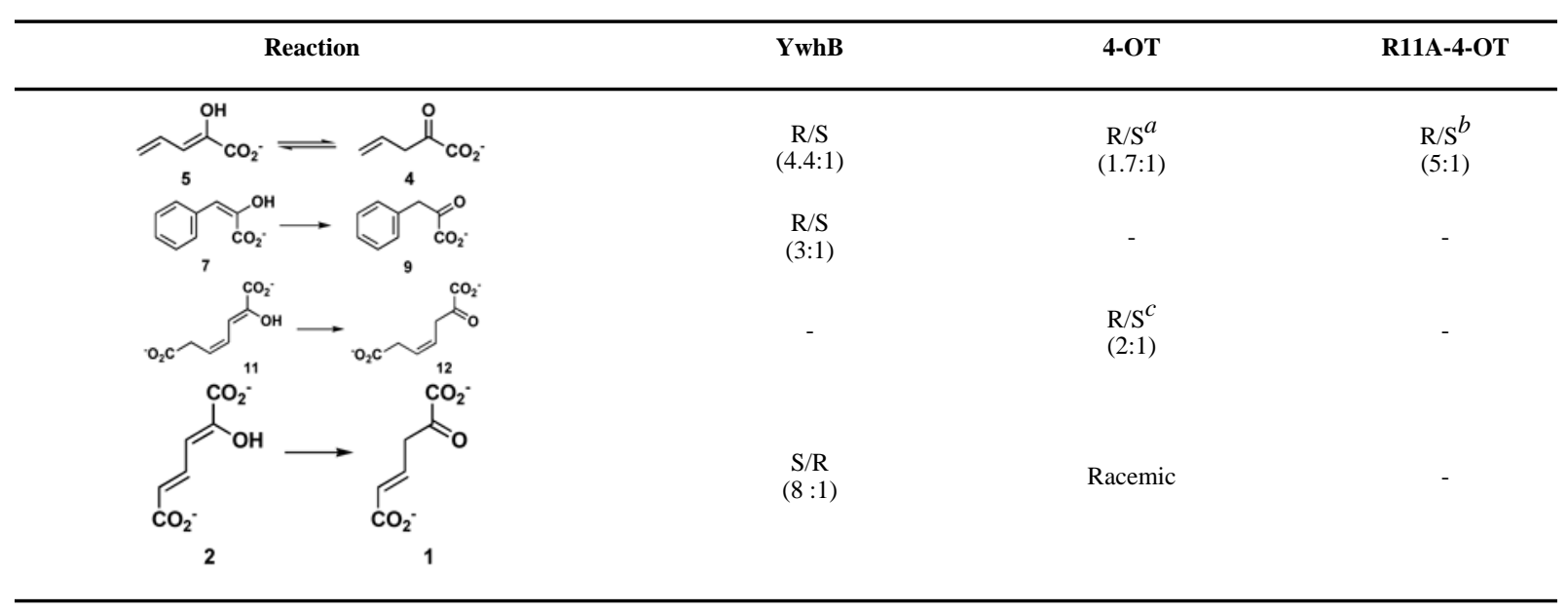

$a_{\text {This result is obtained from reference } 7 \text {. }}$

${ }^{b}$ This result is obtained from reference 13 .

${ }^{c}$ This result is obtained from reference 31 . 